\title{
Paternalism by and towards Groups
}

\author{
Kalle Grill
}

\begin{abstract}
In many or most instances of paternalism, more than one person acts paternalistically, or more than one person is treated paternalistically. This chapter discusses some complications that arise in such group cases, which are largely ignored in the conceptual debate. First, a group of people who together perform an action may do so for different reasons, which makes it more challenging to determine whether the action is paternalistic. This gives us some reason not to pin the property of being paternalistic on actions, since we may alternatively pin it on reasons for actions and allow that these differ between members in the group. Second, the prevention of harmful consensual interactions is sometimes paternalism towards both or all involved, but only if all benefit from interference with themselves rather than with other members in the group, or if all want the harm or risk (more or less) for its own sake. Third, interrelations between three components of paternalism - interference, benevolence and consent - gives us reason to allow that an action can be paternalistic towards some but not others of those affected. This makes it even more difficult, and less relevant, to determine whether or not actions are paternalistic.
\end{abstract}

In the conceptual debate on paternalism, most proposed definitions and characterizations have this approximate form: "An agent A behaves/acts paternalistically towards a person B, if (and only if)...". The controversy then concerns what comes after this phrase, in terms of what sort of action can be paternalistic and what is the role of, respectively, A's motives, the possible justifications for A's behavior, B's consent or lack thereof, B's general competence and current degree of voluntariness, etc. In other words, the discussion presumes, for the most part, that paternalism is something that is done by one agent towards one other agent.

There are certainly cases of one-on-one paternalism, but in many cases, either more than one person acts paternalistically, or more than one person is treated paternalistically. Examples include paternalism by governments and organizations, paternalism by physicians towards groups of patients, and paternalism by parents or teachers towards groups of children. This chapter is focused on such group cases and how they differ from one-on-one cases. By a "group" I simply mean any collection of more than one person, with no assumptions regarding possible shared interests, intentions or other group properties. Groups of individuals in this loose sense sometimes together perform an action or are jointly affected by some action.

If groups can be understood as normative agents and patients in their own right, over and above the individuals they consist of, it seems to me these entities can 
be paternalists and can be paternalized. It would be interesting to explore paternalism by and towards groups in this stronger sense of collective agency and patiency, including the relationship between the individual and the group in cases where the group is a paternalist or a target of paternalism, but some members are not, or vice versa. However, I will not discuss these issues here. Nor will I discuss interesting and important issues around discrimination and prejudice towards groups - communities, classes, nations, etc. - that can lead to their being paternalized. Many issues around group paternalism are under-explored. This chapter is aimed at addressing some of these.

The chapter has three main parts. The first concerns groups as agents of paternalism in relation to a general controversy around whether paternalism resides in actions or rather in reasons for actions. The second and third parts concern groups as patients of paternalism. The second is focused on prevention of consensual interactions that are harmful to at least one party and discusses when such prevention is paternalism. The third discusses more generally how one action that affects many can have different effects on different people and what this means for our analysis of paternalism. [p. 47]

\section{Group paternalists: different people have different reasons}

Paternalism essentially involves some sort of interference or at least involvement with its target (merely thinking about someone cannot be paternalistic) and some sort of benevolent rationale (affecting someone for purely self-interested reasons is not paternalism). There is, in other words, an action component and a reason component to paternalism. I will for the most part refer to the action component as "interference," while leaving it open what this should mean exactly. On some accounts, quite mild influences are sufficient for actions to be potentially paternalistic, and so interfering on my use of the term. I will refer to the reason component as "benevolence" or the "benevolent" or simply "paternalism-making" rationale. ${ }^{1}$

In this section, I will first discuss a general controversy around defining paternalism and then turn to how this controversy is relevant for groups as paternalists. The controversy concerns how the two core components of paternalism - interference and benevolence - are related. Interference is a property of actions and benevolence is a property of reasons. Their interrelation hinges on what sort of thing can be paternalistic. The standard and quite dominant view is that this is actions, and, perhaps in a derived sense, policies, laws, etc., that are produced by actions (influential proponents include Dworkin 1972; Kleinig 1983; VanDeVeer 1986; Shiffrin 2000; de Marneffe 2006). On this action-focused view, whether or not an action is paternalistic is partly determined by its rationale. There are competing accounts of what kind of rationale it is that can make actions paternalistic. The most common idea is that motives are paternalism-makers (e.g. VanDeVeer 1986, Shiffrin 2000), but it is also rather common to point to justification in some sense (e.g. 
Dworkin 1972). Both types of accounts have some intuitive support. It seems paternalistic to force a person into rehab with the motive that this will cure her drug addiction, whether or not this is justified and whatever is the justification for it, if there is one. On the other hand, it also seems paternalistic to force a person into rehab with some other motive and to justify this by invoking the benefit to her. John Kleinig, noting this ambiguity in the concept, proposes at one point that we should avoid talking about either motives or justifications in this context and instead stick with "'having as its rationale', with its explanation/justification ambivalence" (1983: 10). This may indicate a disjunctive definition such that an action is paternalistic if it is either motivated or justified by benevolence. Peter de Marneffe has proposed, to the contrary, a hybrid definition where both motive and justification are required (2006: 73-74).

"Motive" and "justification" are rather vague terms. There are arguably many kinds of motives, some conscious and occurrent, some more subtle, nonoccurrent and less accessible to the agent. Joel Feinberg distinguishes between "conscious reasons" and "deep rationales" (1986: 16). Different psychological theories will divide up the terrain differently. When it comes to justifications, it is problematic to define paternalism in terms of the normative reasons that in fact count in favor of an interference, since whether there are any such reasons depends on the moral status of the phenomena the definition is supposed to capture. Anti-paternalists will typically hold that we usually have no good or valid reasons for benevolent interference. It would be strange if this should cause them to hold that such interference is nonpaternalistic (cf. Husak 2003: 392). It is also problematic to bypass justification and invoke actual outcomes, since an interference may result in a benefit quite unexpectedly, which seems insufficient for making it paternalistic (e.g. you force me into rehab, I suffer terribly and return to addiction, but twenty years later the experience inspires me to write a bestseller, which makes me very happy). Objectively expected outcomes may be more plausible, but this notion needs spelling out and I am not aware that anyone has proposed this solution. It makes more sense, therefore, to invoke what the paternalist takes to be the normative reasons for her action, perhaps mistakenly, which may differ from her motives. There are also, however, the normative reasons that agents officially cite, [p. 48] perhaps only rhetorically. Note that actual normative reasons can be indirectly relevant since if such reasons are identified, agents can then be motivated by them or believe in them or officially point to them. When I speak of "justification" in the following, however, I will only refer, jointly, to the "taking to be" and the "citing as reason" sense.

An alternative to the action-focused view is the reason-focused view. On this view, actions cannot be paternalistic, which may seem unintuitive. Instead, what is paternalistic is the combination of some reasons and some actions (this view is indicated by Kleinig 1983: 12 and by Husak 2003: 390; it is endorsed and defended in Grill 2007). This view is motivated by the fact that antipaternalism is typically directed at reasons for action rather than at actions themselves. J.S. Mill's Liberty Principle, the locus classicus in this context, is not directed at any class of actions, but 
instead rejects benevolence as an unacceptable "end," "purpose," or "warrant" for interference (1859: I.9). An advantage of the reason-focused view is that, unlike the action-focused view, it need not distinguish between different kinds of rationales. Both the action-focused and the reason-focused view must specify what actions count as interfering and what contents of reasons count as benevolent or paternalismmaking. However, only the action-focused view must then go on to say, for any combination of benevolent rationales, whether this combination makes the action paternalistic. For example, assume A forces B into rehab motivated by benefits to B but seeing benefits to others as the justification, and also forces $\mathrm{C}$ into rehab motivated by benefits to others but seeing benefits to $C$ as the justification. An actionfocused definition of paternalism must be specified so as to determine, for each of these actions, whether or not it is paternalistic. The reason-focused view, in contrast, will imply that it is paternalistic to be motivated by B's good to force her into rehab, and paternalistic to see and/or cite C's good as a reason for forcing $\mathrm{C}$ into rehab, while neither action is paternalistic as such.

I have so far discussed what I have called "kinds" of rationales, divided into motives and justifications, each category arguably containing several subcategories, with normative reasons a possible third category. That one and the same action often has several different kinds of rationales is one complexity faced by anyone who aims to determine the status of an action based on its (overall) rationale. Another such complexity is that there are also often many rationales of any one kind, differing in content or substance. We may, for example, be motivated to force a person into rehab both for her own sake and for the sake of her family. On the reason-focused view, it is the motives themselves, in combination with the interference that they are motives for, that are paternalistic. Hence, one motive for an action can be paternalistic while another is not. That there are many rationales of many kinds raises no special problems on this view. On the action-focused view, however, we must determine whether or not an action that has multiple rationales is paternalistic. Scholars have offered different proposals, including that an action is paternalistic if benevolence is its only rationale (Gray 1983: 90), its main one (Archard 1990), or even just $a$ rationale, however marginal (Bullock 2015).

Actions with both paternalism-making and other rationales are sometimes called "mixed cases" and treated as a sort of exception. Authors who take this path typically go on to focus exclusively on unmixed cases. This leaves it an open question how mixed cases, i.e. most actual cases, should be treated. Kleinig has two proposals in this regard. One is that actions should be considered paternalistic to the extent that their rationales are paternalism-making (Kleinig 1983: 12; also endorsed by Clarke 2002: 82-83). It is not clear, however, how this should be spelled out. Most obviously, the extent to which the rationale for an action is benevolence can be measured either in absolute terms - how strong is this rationale taken in isolation? - or in relative terms - how strong is this rationale relative to other rationales for the same action? Neither of these specifications, however, takes into account how strong a rationale is required for the action to be [p. 49] all things considered motivated or justified. On either 
specification, actions can be quite paternalistic even if they are fully motivated and justified by non-benevolent rationales (as argued in Grill 2007: 446-8). Perhaps, therefore, "to the extent" should be understood in some kind of relation to how strong of a total rationale is required for action, in either motivational or justificational terms. Alternatively, as indicated by Kleinig's second proposal (Kleinig 1983: 12; also endorsed by de Marneffe 2006: 74), an action can be considered paternalistic if benevolence is required for the action to be all things considered motivated, or justified, or either motivated or justified, or both motivated and justified.

The complexities that arise because actions have multiple rationales (in terms of content) and multiple kinds of rationales are aggravated when paternalists are groups, because different individuals often have different rationales for their actions. Call this the diversity problem. Hundreds of lawmakers in parliament, for example, may all vote for the same intrusive law for slightly different reasons, e.g. benefits to those intruded upon, benefits to others, environmental benefits, loyalty to one's party, advancing one's career, etc. Proposals for when mixed cases are paternalistic can be adapted from one-on-one cases to groups, though they may seem (even) less appealing in this context. On the strongest account, where benevolence must be the only rationale, this will supposedly apply to all members, classifying as nonpaternalistic group actions where a single member has some other rationale mixed into his set of rationales. On the weakest account, where benevolence need only be present as a rationale, it is supposedly sufficient that this rationale is present for a single member. On in-between accounts, the threshold for what counts as the "main" reason must in group cases be defined in relation to more than one person, raising new issues. For example, in determining what is the main rationale for the group, are we to go by how many members have benevolence as their main rationale, or are we to aggregate some other way, perhaps to take into consideration how strong are different members' total rationales for action (e.g. how strongly motivated they are)? On the "to the extent" account, similar issues arise concerning how to aggregate over members. I see no reason to believe that these issues are unresolvable. The point is that this is work that has not been done and that must be done before the various proposals can be applied to group cases.

The diversity problem is noted by Douglas Husak in the context of legal paternalism (Husak 2003: 389-91). Husak also notes that it is difficult to know what motivates lawmakers and that laws remain in place over time and so the same law can be supported for different reasons as times change (2003: 391). Because of these problems, Husak considers something like the reason-focused view. However, despite many reservations, he insists in the end that laws can be paternalistic, and suggests that, because of the problems with motives, we should go by a law's "best rationale" (2003: 392). ${ }^{2}$ However, as Husak admits, this view has the general problem, described above, that it will classify all actions and laws as nonpaternalistic if benevolence is in fact never a good normative reason for interference. This could possibly be avoided by referring, not to actual reasons, but instead to facts that would be reasons in other contexts, such that the "best rationale" for an action is the rationale that would be 
best, if, counterfactually, protection and promotion of a person's interests provided as strong normative reasons for interference as they in fact do for responding to requests for help, or some such construction.

More to the point, it is not obvious that invoking actual normative reasons will avoid the diversity problem, since each member of a group may contribute in a different way to some group action and may each have different reasons for their respective contributions. Consider the case where $\mathrm{A}, \mathrm{B}$ and $\mathrm{C}$ each contribute to building a wall that will protect $D$ from foolishly balancing on the edge of a cliff. Perhaps A raises the funds, $B$ makes the plans, and $C$ does [p. 50] the actual construction. They may all correctly believe that the immediate outcome of their joint action - that there will be a wall - is a good thing because it reduces the risk of harm to D. However, their main and sufficient actual normative reasons for contributing may not be the effect on $\mathrm{D}$, but rather, e.g., that they have promised to contribute, that they will themselves be morally better people for contributing, or that contributing will bring them resources - salaries, reputation - that will enable good deeds in the future (feeding their children, building greater walls). Depending on one's general normative views, it may or may not be the case that we always have some reason to contribute, when we can, to other people's welfare, e.g. by reducing risk to them. If we don't, A, B and C may each have no benevolent reason whatsoever to build the wall. If we do, the benevolent reason they have may be relatively weak, and redundant. Though having a redundant benevolent motive may possibly taint an action as paternalistic on motivational accounts, it seems extreme to hold that redundant normative reasons make actions paternalistic. Therefore, it may be true for each of $\mathrm{A}$, $\mathrm{B}$ or $\mathrm{C}$ that the rationale for their action, such as it counts in this context, is nonbenevolent. It may of course also be that their rationale is benevolent, and so the diversity problem remains unsolved.

We could set aside individual reasons and look more generally at the reasons for, e.g., there being a wall. Indeed, this approach is common when discussing laws; there are supposed to be reasons for and against laws as such, supposedly for and against their existence. Husak expresses himself this way, as does Joel Feinberg. For Feinberg, laws are paternalistic if their "implicit rationale" is benevolent. This is, Feinberg explains, a sort of general understanding regarding the function of the law, explaining why it remains in place (1986: 17). I think we do best to interpret talk of practical reasons for other things than actions as shorthand for reasons for actions, such as introducing a bill or voting for it, or financing, planning or constructing a wall. If we allow ourselves to talk non-reductively of reasons for such things as the existence of laws and of infrastructure, it is unclear how this bears on agents and their reasons. With paternalism in particular, with its strong connection to interpersonal relationships, motivations and attitudes, jettisoning this connection is quite radical.

On the reason-focused view, diversity does not pose as much of a problem, since it can be accommodated by counting as paternalism any combination of interfering actions and benevolent rationales for those actions, rationales of any kind (motives, justifications, etc.). When $A$ and $B$ together force $C$ into rehab, for example, A's motive 
may be to help C, while his justification is to protect C's family (who are innocent, more vulnerable, etc.). B, on the other hand, is more motivated by concern for C's family, but his justification is to help $\mathrm{C}$ with his drug problem (since he suffers the most, etc.). Depending on the details of a reason-focused view, it may be that, in relation to the interfering action, A's motive but not his justification is paternalistic, while B's justification but not his motive is paternalistic. The example is a simple one, however, and for more complex cases, the reason-focused view will imply that paternalism is sprinkled over a vast net of actions and reasons, making for a very long and complicated answer to the question "is this paternalism?".

Before I go on to discuss paternalism towards groups, in the next section, I will briefly note one complication that does not directly have to do with reasons for action. In the example with the building of the wall, three different agents have different reasons for action. However, they also contribute differently to the collective action of "building the wall." It is not obvious that all contributions amount to interference. Perhaps just raising the funds for the project is not interfering, or perhaps just doing the work that is ordered by someone else is not interfering. More generally, someone could perhaps contribute to an outcome that seems, on the face of it, to involve interference, without thereby interfering herself. Perhaps in such cases, the interference can only be found on the level of collective agency, just as with collective actions that seem [p. 51] benevolent though none of the contributing agents act benevolently. If so, this is a complication for both the action-focused and the reasonfocused views, since both presume an account of interfering action.

\section{Paternalized groups I: preventing consensual interactions}

The discussion so far has been focused on paternalist groups. All issues that I have discussed can arise whether the paternalized is one person or several. In this section and the next, I will focus on actions that target groups, whether or not the agent is an individual or a group. Such actions can be interfering for some and not for others, and can be benevolent towards some and not others. Therefore, not all cases I will discuss are cases of group paternalism. Instead, one of my aims is to clarify which cases are and in what sense. As part of my discussion I will refer to concrete examples, such as drug regulation, and assume that the prevented activity, such as buying and using drugs, is indeed harmful. I make this assumption only for the sake of argument, since interactions that are not harmful to anyone should rather obviously not be interfered with and so are not very interesting to discuss. I will throughout speak of "harm" and "benefit" as outcomes, with the understanding that how these outcomes are relevant to paternalism depends on one's view of the reason component - actual outcomes may provide normative reasons, believed outcomes may be motivating and invoked as justification, etc.

I emphasized above that there can be several rationales, with different content, for the same interfering action. This can be because there is more than one reason to interfere with the same person, e.g. both to promote her well-being and to respond to 
a request for help from her. More often, however, it is due to effects on more than one person. If we interfere with two persons who are doing something that will harm one of them, we may be interfering with one to prevent harm to self and with the other to prevent harm to others. Sometimes, as Gerald Dworkin explains, "in trying to protect the welfare of a class of persons we find that the only way to do so will involve restricting the freedom of other persons besides those who are benefitted" (1972: 68). Dworkin labels such cases "impure paternalism," where the impurity is the interference with some other party, in addition to the beneficiary. ${ }^{3}$

The standard case of impure paternalism is interference with consensual interactions, and in particular with such interactions as are harmful to one of the parties and not the other. Examples include such extraordinary interactions as consenting to being abused or killed, and selling oneself into slavery. More practically relevant examples include selling sexual services and buying unhealthy consumer goods, such as recreational drugs. Interference will benefit the party that is harmed in its absence. There is presumably no benefit to the other party, e.g. the seller of drugs or the buyer of sex. Therefore, assuming the beneficiary is a single individual, this is not a group case. Interference with other parties is just a means, perhaps a necessary means, to producing the benefit. These parties are not themselves thereby paternalized. It is an interesting question whether we have any reason to regret, for the sake of the harming party, interference with actions that harm consenting others - such as selling them drugs. This issue, however, is independent of issues to do with paternalism.

In many typical cases of impure paternalism, such as prohibition of the sale of unhealthy products, the interference is most obvious with the nonbeneficiary, i.e. the seller (who may be prosecuted and punished). However, what makes the case one of paternalism is that there is also interference with the buyer, who is prevented from acquiring the desired good or service. As Feinberg argues, if others are prevented from selling me what I want to buy, or aiding me [p. 52] in my pursuits, then $I$ am interfered with and my freedom is limited (Feinberg 1986: 9). Or, in Mill's words:

there are questions relating to interference with trade, which are essentially questions of liberty [...] where the object of the interference is to make it impossible or difficult to obtain a particular commodity. These interferences are objectionable, not as infringements on the liberty of the producer or seller, but on that of the buyer. (1859: V.4)

Some authors describe as impure or "indirect" paternalism cases where they claim there is no interference with the beneficiary/buyer, but only with the nonbeneficiary/seller (Pope 2003: 687-88; Le Grand \& New 2015: 37). If this was a form of paternalism, it would perhaps be a special kind of group case, involving two different members in quite different roles - one is interfered with and another benefits. However, it is unclear what the paternalism would consist of in such cases. Interference with one person in order to benefit another person is the standard 
contrast class to paternalism (preventing assault has this structure). If there is indeed no interference with the buyer, then, I propose, there is no paternalism, but only interference to prevent harm to others (Bayles 1973 and Hansson 2005 argue that many prohibitions of consensual interactions should be understood in this way).

Here, I should make an exception to my loose use of "interference" and acknowledge that some authors offer very wide understandings of interference, or, in other words, reject the assumption that paternalism is interfering. For example, Cass Sunstein and Richard Thaler claim that it is sufficient that there is an attempt to "influence choices" (Sunstein and Thaler 2003: 1162) and Danny Scoccia claims that any benevolent influence on another via "nonrational means" is paternalistic (Scoccia 2013: 76, as well as his chapter in this volume). Such actions may not warrant the label "interference." In the present context, however, what is important is that however we specify the action component of paternalism, actions belonging to this type must be directed at the beneficiary for there to be paternalism. It is not sufficient that some other person is the target of such an action. If we require coercion, then there must be coercion towards the beneficiary. If we require only influence on choice, then there must be influence on the choice of the beneficiary.

Some harmful consensual interactions are symmetrical in the sense that both or all parties harm each other and also consent to being harmed. Boxing is the traditional example, mixed martial arts competitions a more recent one. A street fight with willing participants is a more clear-cut example, without the commercial and institutional context. Benevolently interfering with consensual fighting may seem a clear example of paternalism, since there is both interference with and benefit to all members of the group. However, the details are somewhat intricate. Suppose that in a group consisting of $\mathrm{A}, \mathrm{B}$ and $\mathrm{C}, \mathrm{A}$ wants to punch $\mathrm{B}, \mathrm{B}$ wants to punch $\mathrm{C}$ and $\mathrm{C}$ wants to punch $A$. If $D$ prevents any punching from occurring by separating $A, B$, and $C$, this seems clearly to interfere with each of them by stopping them from punching the person they want to punch, while also benefitting each of them by protecting them from being punched. However, such prevention does not seem paternalistic because no person benefits from the interference with her (assuming they are not harmed by delivering a punch). They all benefit from the interference with other people, from which they are protected.

Now consider a street fight with two willing participants, perhaps supporters of opposing sports clubs who take pride in fighting "for their team." We could claim that keeping these brawlers apart prevents A from fighting B, for B's sake, and prevents B from fighting $A$, for A's sake, hence benefitting each party only by interference with the other. However, this seems less [p. 53] plausible than in the three party case, since both A and B want the same thing to happen - for there to be a fight between the two of them. They want this, let us assume, because they consider the risk of harm a fair price to pay for the thrill and the social recognition they get from fighting. Like the willing buyer of drugs or seller of sex, each brawler invites another person to (potentially) harm him. Like in these other cases, therefore, the 
freedom of each brawler is limited by preventing him from engaging in a harmful consensual interaction.

I have argued that interference in the two party brawling case is paternalistic while interference in the three party punching case is not. Let me expand on the relevant difference. It is not that the two brawlers would object to interference. The three punchers too may object, because they value the opportunity to punch the person they want to punch more than they value the protection from being punched. The relevant difference is not in the numbers either. Two people may both want the other to suffer a punch, more than they want to be protected from being punched themselves, and so be opposed to interference. I believe interference in these variations on the punching case would not be paternalism. The important distinction is, I believe, between two sorts of cases: first, those where a person wants some harm or risk of harm for its own sake, or where this harm or risk is integral to what he wants, as in the brawling case - part of what the brawlers take pride in is exactly to risk harm "for their team" - and, second, those where a person is prepared to accept some harm or risk of harm in order to get something that he wants more than to avoid this harm or risk, such as to inflict harm on someone else. In the former cases, prevention is interference with the person who wants the harm or risk. In the latter case, prevention is interference only with the source of the harm or risk and not with the person who is prepared to accept it. This distinction is relevant only when the source of harm or risk is another agent (and probably only when that agent causes harm or risk intentionally). When the source of harm is the person herself, we can (normally) protect her only by interfering with her, which is paternalism. ${ }^{4}$

Special considerations apply when a person is opposed to being protected by others, even if she does not want the harm or risk that may result from being unprotected. Scoccia (2013: 81) notes that some people are "committed to an extreme ideal of self-reliance" and therefore oppose benevolent interference even with their own substantially involuntary action. People may for similar reasons oppose benevolent interference even with their own attackers - they want to "fight their own battles." The state of being unprotected, or independent, is one to which risk is an integral aspect - it is just this risk that one does not want others to remove. I therefore propose that interference with committedly self-reliant people is paternalism.

Similar considerations apply when interferences with consensual interactions are coordinated through systems, institutions or laws. A law that prevents people from harming themselves, or from soliciting the aid of others in harming themselves, involves paternalism (i.e. implementing it, or doing so for certain reasons, may be paternalistic). As for a law that prevents people from harming others without their consent, but that is universally opposed, whether or not it involves paternalism depends on whether the opposition is based on a desire for self-reliance, or on a desire for the opportunity to harm others. In other words, it depends on whether people want to be unprotected themselves, or whether they want others to be unprotected. In many cases, of course, members of a group will have different aims, 
opinions and ideals. This and other differences between individuals is the topic of the next section.

\section{Paternalized groups II: different effects on different people}

In this section, I will first note and illustrate how one action can affect different people differently in ways relevant to paternalism. I will then move on to discuss how this may influence our [p. 54] classification of various cases as paternalistic. The relevant differences concern, first, the two core components of paternalism already identified: who is interfered with and who benefits. A third relevant difference is also a third component of paternalism: the will component. Benevolent interferences are typically considered paternalistic only when they are against the will of the target, i.e. when unwelcome or not consented to. This component is arguably not essential since it can be integrated into the action component such that an action counts as interfering only if it is not consented to. However, it is typically treated as a separate component and I started to treat it as such towards the end of the previous section, in considering whether interference with brawling and punching would be objected to.

For there to be paternalism, then, an action must be unwelcome, interfering and benevolent. However, I argued in the previous section that this is not sufficient, because sometimes the benevolence towards one person is not connected to the interference with her, as when the three punchers are all prevented from harming each other. What is relevant is not whether the action is benevolent, but whether the interference is benevolent. It can also be questioned whether an unwelcome benevolent interference with a person is paternalistic towards her if her objection is not connected to the interference with her (e.g., A stops $B$ and $C$ from daring each other into jumping off a cliff; both B and C object to A's interference; B does not want to jump and would not object but for the fact that she really wants $C$ to jump). There are, potentially, interconnections between the three components and these connections can be different for different people affected by the same action. This indicates that we should allow, as I started to do in the previous section, that one and the same action can involve paternalism towards some and not towards others. This indicates important modifications of both the action-focused and the reason-focused view, as both of these otherwise deal only in actions and not their diverse effects on different people. On the reason-focused view, the modification can be integrated by holding that what is paternalistic is not combinations of actions and their rationales, but rather combinations of rationales and (unwelcome) interferences with particular people. This makes for an even more complex but arguably more accurate analysis of paternalism in group cases. On the action-focused view, similarly, the modification could be taken to imply that what is paternalistic is not in fact actions but rather interferences with particular people.

Feinberg (1986: 20) discusses this modification and dismisses it as "an unnecessary relativizing of the concept" of paternalism. However, his discussion of group cases is quite limited, as I will soon explain. Given the mentioned 
interconnections and also given the general individualism inherent in the liberal tradition, it makes much sense to base analysis of paternalism towards groups on the effects on individual members.

I will now survey some examples of actions towards groups that are paternalistic towards some members but where one of the three components of paternalism is missing in relation to other members. First, missing benefits: prevention of consensual interactions that are harmful to only one party is one sort of case; another is the subjection of a group to a measure that protects only those that are vulnerable to some harm. An example is removing the sleeping pills or cigarettes from a shared home, benefitting the cohabitant who is suicidal or a habitual smoker, but only harming the cohabitant who is neither of these things but sometimes has trouble sleeping or enjoys a single cigarette. Just as for prevention of consensual interactions, only the interference with the beneficiary is paternalistic. The interference with nonbeneficiaries is a sort of collateral damage. ${ }^{5}$ Unlike some cases of preventing consensual interactions, those that suffer this damage are not harming anyone or doing anything morally problematic, and so the interference with them must be considered a negative.

Second, missing interference: speed limits supposedly benefit drivers by reducing the risk of accident for them, but also of course reduce risks for cyclists and pedestrians Even if pedestrians [p. 55] (who never drive) are included among the intended beneficiaries, and even if they are for some reason opposed to the regulation, it is not paternalistic towards them because it does not interfere with them.

Third, missing objection: many people appreciate that product safety legislation prevents them from buying unsafe machinery or consumer goods. Others oppose such restriction of their freedom, on either pragmatic or principled grounds. Libertarian chainsaw buyers are paternalized by the state, while most other customers are not.

There is very little discussion in the literature of how, on the dominant actionfocused view, we should classify the surveyed examples. However, a number of influential contributions in the 1980s converge on a view we may call the willing majority view: for actions that interfere with and benefit all members of a group, if a majority consents and the action is motivated by its benefits to them, then the action is not paternalistic, though it may be unfair to nonconsenters (Arneson 1980: 471-2; Dworkin 1983: 110; Feinberg 1986: 20). The view is motivated by discussion of such cases as the prohibition on dueling and the fluoridation of drinking water, where a large majority favors the policy and it is implemented for their sakes. The willing majority view can be specified to different motivational accounts (one motive, main motive, only motive, implicit rationale, etc.) and can be transformed into a justificational account by substituting, e.g., "taken to be justified" or "claimed to be justified" for "motivated." The view still draws scholarly support (e.g., Le Grand \& New 2015: 21-22). 
The willing majority view says that, in some cases where the rationale for an action is to benefit a majority of those affected and where this majority is not paternalized, the action is not paternalistic. However, the view is restricted to cases where all those affected are both interfered with and benefitted and where the reason the majority is not paternalized is that they consent. This is the third of the cases just surveyed - missing objection. The spirit of the view, however, indicates that its proponents would not mind a generalization that incudes also missing benefit and missing interference.

The willing majority view categorizes actions based on their different effects on different people. Given the idea that paternalism actually resides in interferences with particular people and not in actions, the view may seem superfluous. If we know that an action is an unwelcome benevolent interference with $\mathrm{A}$ and with $\mathrm{B}$ but not with $\mathrm{C}$, it is not clear what additional information is conveyed by saying that the action itself is or is not paternalistic. Those nevertheless committed to pinning the predicate "paternalism" on actions have some work to do. Even the generalized willing majority view is applicable only to actions that are nonpaternalistic towards a majority. A simple addition would be to categorize as paternalistic those actions that are paternalistic towards a majority. However, the $50 \%$ cut-off point seems arbitrary. It might also seem that factors other than sheer numbers could be relevant, such as the size of the benefits involved. Suppose that the prohibition of some rare and dangerous drug will marginally reduce the already very low risk that the majority ever confront this drug. The prohibition is introduced and the majority welcomes it for this reason. However, the prohibition will also drastically reduce the high risk of drug abuse and ensuing harm to some minority, who are opposed to prohibition. This prohibition will count as nonpaternalistic on plausible specifications of the willing majority view, which may seem counter-intuitive (on the importance of relative benefits to group consent, see Grill 2009: 151-53).

A further problem with the willing majority view is that it disregards the reasons for why people consent to interference with a group to which they belong, as briefly indicated above. Proponents tend to assume that the consenters consent out of self-interest, but they may instead be altruistically motivated, consenting for the sake of the nonconsenters, whom they see as failing to act in their own best interest. This raises the question whether altruistic consent renders [p. 56] interference nonpaternalistic towards consenters. In addition, given that some people's altruistic consent makes blanket interference more likely, these people seem to be using their consent to indirectly paternalize nonconsenters. If the consenters are in the majority, the willing majority view would categorize the interfering action as nonpaternalistic. This seems very questionable. We could modify the view to require a majority of selfinterested consenters, but there are many additional issues to consider, such as how to count members who consent partly for self-interested and partly for altruistic reasons, and how to count liberally minded altruists who do not consent, in order to protect consenters whom they see as failing to give proper priority to their own 
liberty and independence (on these and other issues around group consent, see further Grill 2009).

Before I conclude, let me briefly mention a fourth potentially relevant difference in how people are affected by the same action: who, among those interfered with, is acting voluntarily or competently. Though it has been convincingly challenged (Hanna 2011), it is a quite dominant position that unwelcome benevolent interference is not morally problematic, or much less so, when and because it is directed at choices or actions that are below some threshold of voluntariness. Following Feinberg, such interference is often called "soft paternalism." If some of those interfered with are below the threshold and some not, this situation is analogous to that when only some group members are interfered with or benefitted or objecting, though now the difference is not between paternalism and nonpaternalism, but between hard paternalism and soft paternalism. We could then either be content to determine for each paternalized member of the group whether the paternalism towards her is hard or soft, or we could identify some rule for whether or not the interfering action is soft or hard paternalistic, which should be suitably sensitive to differences among group members.

\section{Conclusion}

Though examples of paternalism in the conceptual and normative debate often include groups both as paternalists and as paternalized, the interesting and difficult issues that groups raise are seldom explicitly discussed or analyzed. What little has been said in the literature on paternalism by and towards groups is quite cursory. The topic deserves more thorough treatment. I have focused in this chapter on some issues that arise from the mere fact that more than one person is either paternalizing or being paternalized, setting to one side issues to do with collective agency and patiency in any stronger sense.

In section 1, I presented the action-focused and reason-focused views on paternalism and explained how groups as paternalists complicate both views but provide greater challenges for the action-focused view, on which actions must somehow be categorized as either paternalistic or nonpaternalistic based on the often rich and diverse total rationale for group interference.

In section 2, I argued that standard cases of impure paternalism are not paternalism towards groups because they only benefit (or are only believed to benefit) one party. I also argued that if they do not interfere with the beneficiary, they are not paternalism at all. I went on to consider interferences with people who mutually harm each other and argued that these are paternalistic only if the affected people benefit via interference with themselves, not others. I proposed that interference with two or more people bent on harming each other can be paternalism if they seek to be harmed or put themselves at risk of harm, or if they seek an activity where such harm or risk is an integral aspect. In other cases, interference is not 
paternalistic, even if objections to interference may have normative significance in other ways.

In section 3, I argued that, because of interrelations between the three components of paternalism - interference, benevolence, and will - we should understand paternalism in terms [p. 57] of unwelcome benevolent interferences with particular people, rather than in terms of actions, which may paternalize some and not others (when an action only affects one person, we need not distinguish between interference and action). This shift from action to interference holds for both the action-focused and the reason-focused view. There may be a connection between this shift and the controversy between action-focus and reason-focus in that, if we give up trying to pin the predicate "paternalistic" on actions, we may as well accept the reason-focused view, modified to deal in reasons for interferences rather than reasons for action. ${ }^{6}$

\section{Related Topics}

Hard and Soft Paternalism; Libertarian Paternalism, Nudging and Public Policy; Paternalism and the Criminal Law; Perfectionism and Paternalism; The Concept of Paternalism.

\section{Notes}

${ }^{1}$ Shiffrin (2000) is an exception to the near consensus that paternalism essentially involves the protection or promotion of the interests of the person interfered with. Shiffrin clearly states that the paternalism-making rationale can be the improvement of things under a person's control that are not, strictly speaking, her interests. However, she seems to presume that the rationale must be benevolent in some sense. Presumably, she would not categorize as paternalist interference that is solely motivated by self-interest, or by sheer malice. I will throughout use standard examples that do not cohere with Shiffrin's view, but which can be reformulated so that they do.

2 The difficulty with group motives has been noted more often in the context of liberal neutrality. Neutrality can fruitfully be understood in terms of a constraint on what reasons may be invoked for political decisions (e.g. Larmore 1987: 44; Wall 1998: chap. 2; de Marneffe 2010: chap. 5, esp. 134). Antipaternalism can similarly be understood in terms of what reasons may be invoked for interference (Grill 2015). So understood, neither of these liberal "-isms" is dependent on classifying actions or laws as non-neutral or paternalistic. ${ }^{3}$ Feinberg complains that "impure" sounds like "a watered down sort" of paternalism and proposes to use "indirect" instead (Feinberg 1984: 9). Both terms are used, sometimes with the same meaning and sometimes with slightly different meanings.

${ }^{4}$ This analysis of consensual fighting partly contradicts that in my (2007: 453-55). A note on terminology: In my (2007) I speak of different effects of actions in the abstract, noting that effects can be individuated by what person is affected but leaving it open that other factors may also be relevant. This framework may sometimes be useful, but here, for ease of presentation, I bypass talk of effects in general and speak only of interference with and paternalism towards different people. 
5 If interfering with nonbeneficiaries is "the only way" to attain the benefit to the beneficiaries, then these cases are impure paternalism on Dworkin's characterization. However, this concept is usually only associated with interference with consensual interactions.

${ }^{6}$ Thanks to Jason Hanna and Lars Samuelsson for very helpful comments on more than one draft.

\section{References}

Archard, D. (1990) "Paternalism Defined," Analysis 50: 36-42.

Arneson, R. (1980). "Mill versus Paternalism," Ethics 90: 470-489.

Bayles, M. D. (1974) "Criminal Paternalism," in J.R. Pennock and J.W. Chapman (eds.), The Limits of Law - Nomos XV, New York: Lieber-Atherton, pp. 174188.

Bullock, E.C. (2015) “A Normatively Neutral Definition of Paternalism," The Philosophical Quarterly 65: 1-21.

Clarke, S. (2002) "A Definition of Paternalism," Critical Review of International Social and Political Philosophy 5: 81-91.

Dworkin, G. (1972) "Paternalism," The Monist 56: 64-84. [p. 58]

Dworkin, G. (1983) "Paternalism: Some Second Thoughts," In R. Sartorius (ed.), Paternalism, Minneapolis: University of Minnesota Press, pp. 105-111.

Feinberg, J. (1986) The Moral Limits of the Criminal Law, Volume 3: Harm to Self, New York: Oxford University Press.

Gert, B., and Culver, C.M. (1976) "Paternalistic Behavior," Philosophy \& Public Affairs 6: 45-57.

Gray, J. (1983) Mill on Liberty: A Defence, London: Routledge.

Grill, K. (2007) "The Normative Core of Paternalism," Res Publica 13: 441-58.

Grill, K. (2009) "Liberalism, Altruism and Group Consent," Public Health Ethics 2: 146-57.

Grill, K. (2015) "Antipaternalism as a Filter on Reasons," in T. Schramme (ed.) New Perspectives on Paternalism and Health Care, Cham, Switzerland: Springer, pp. 47-66.

Hanna, J. (2011) "Paternalism and Impairment," Social Theory and Practice 37: 43460.

Hansson, S.O. (2005) “Extended Antipaternalism,” Journal of Medical Ethics 31: 97100.

Husak, D.N. (2003) “Legal Paternalism," in Oxford Handbook of Practical Ethics, New York: Oxford University Press, pp. 387-412.

Kleinig, J. (1983) Paternalism, Manchester, U.K.: Manchester University Press.

Le Grand, J. and New, B. (2015) Government Paternalism: Nanny State or Helpful Friend? Princeton, N.J.: Princeton University Press. 
Larmore, C.E. (1987) Patterns of Moral Complexity. Cambridge: Cambridge University Press.

de Marneffe, P. (2006) "Avoiding Paternalism", Philosophy \& Public Affairs 34: 68-94.

de Marneffe, P. (2010). Liberalism and prostitution, New York: Oxford University Press.

Mill, J.S. (1859) On Liberty, London: J.W. Parker and Son.

Pope, T.M. (2003) "Counting the Dragon's Teeth and Claws: The Definition of Hard Paternalism," Georgia State University Law Review 20: 659-722.

Scoccia, D. (2013) "The Right to Autonomy and the Justification of Hard Paternalism," in C. Coons and M. Weber (eds.), Paternalism: Theory and Practice, New York: Cambridge University Press, pp. 74-92.

Shiffrin, S. (2000) "Paternalism, Unconscionability Doctrine, and Accommodation," Philosophy \& Public Affairs 29: 205-50.

Sunstein, C.R. and Thaler, R.H. (2003) "Libertarian Paternalism Is Not an Oxymoron," The University of Chicago Law Review 70: 1159-1202.

VanDeVeer, D. (1986) Paternalistic Intervention: The Moral Bounds of Benevolence, Princeton, N.J.: Princeton University Press.

Wall, S. (1998) Liberalism, Perfectionism and Restraint, Cambridge: Cambridge University Press. 